\title{
Adsorption of Spilled Oil from Seawater by Waste Plastic
}

\author{
A.K. Aboul-Gheit ${ }^{1}$, F. H. Khalil'² and T. Abdel-Moghny' \\ 1 Egyptian Petroleum Research Institute, Nasr City -7th Region, 11727, Cairo - Egypt. \\ 2 National Centre for Radiation Research and Technology, Atomic Energy Authority, P.O.29, Cairo - Egypt \\ E-mail: Thanaa_h@yahoo.com - aboulgheit2000@hotmail.com
}

Résumé - Rémédiation de pollution par l'huile par des déchets plastiques - Deux problèmes écologiques sont considérés dans ce travail. Un des problèmes est de trouver une application utile des déchets de plastiques, polyéthylène $(\mathrm{PE})$ et polypropylène $(\mathrm{PP})$, qui augmentent jour après jour partout dans le monde. Le deuxième problème est la rémédiation de pollution par l'huile dans des environnements aquatiques. Nous avons utilisé le PE et les poudres feuilles de PP pour absorber l'huile dans de l'eau, par simple contact pendant quelques minutes. L'effet sur l'activité des polymères de soumettre les poudres et les feuilles à une faible dose de radiation $\gamma$ (3 Mrad) a été étudiée. L'examen des polymères avant et après absorption d'huile par calorimétrie différentielle (DSC) et par microscope électronique de balayage (MEB) a permis d'éclaircir les comportements de ces polymères.

\begin{abstract}
Adsorption of Spilled Oil from Seawater by Waste Plastic - Two environmental problems are encountered in this work. A solution of one problem is to find a useful application of the waste plastics; polyethylene (PE) and polypropylene (PP), which increases day after day all over the world. The second problem is the oil spill in aquatic locations. We used PE and PP waste powders and sheets to sorb the oil from water, via simple contacting for few minutes. The effect of subjecting the powders and sheets to a low dose of $\gamma$-irradiation $(3 \mathrm{Mrad}$ ) on the activation of the current polymers was investigated. Differential scanning calorimetric (DSC) and scanning electron microscopic (SEM) examinations of the neat and oil sorbing polymers were performed to throw light on the behaviours of these polymers.
\end{abstract}




\section{INTRODUCTION}

Development of the oil sorbents made of organic waste materials was initiated in order to provide resources for marine oil spill response with less environmental load and cost [1]. Sorbents of the oil spill in water are materials that soak up the oil. They can be used to recover oil through the mechanisms of absorption and adsorption, or both. Absorbents allow oil to penetrate into pore spaces in the material they are made of, while adsorbents attract oil to their surfaces but do not allow it to penetrate into the material. Once sorbents have been used to recover oil, they must be removed from the water and properly disposed of on land or cleaned for reuse. Any oil that is removed from the sorbent materials must also be disposed of or recycled. Sorbents can be divided into three basic categories: natural organic, natural inorganic and synthetic. The first category includes peatmoss, straw, hay, sawdust, ground corncobs, feathers, and other carbon-based products. They are relatively inexpensive and generally readily available. Organic sorbents can absorb 3 to 15 times their weight of oil, but they do present some disadvantages. Some organic sorbents tend to absorb water as well as oil, causing them to sink. Many organic sorbents are loose particles, such as sawdust, and are difficult to collect after they are spread on the water [2].

Natural inorganic sorbents include clay, perlite, vermiculite, glass, wool, sand, and volcanic ash. They can absorb from 4 to 20 times their weight of oil. Inorganic substances, like organic substances, are inexpensive and readily available. Most organic materials can only be used on land and are not adaptable to water use for oil spill cleanup. Synthetic sorbents includes man-made materials that are similar to plastics, such as polyurethane, polyethylene, polypropylene, and nylon fibers. Most synthetic sorbents can absorb as much as 70 times their weight of oil. Synthetic sorbents that cannot be cleaned after use can present difficulties because they must be stored temporarily until they can be disposed of properly. They are best suited to absorb lighter viscosity oils that can perpetrate or wick into its fibre [2].

Sorbents work by either absorption or adsorption [2]. Absorbents operate like sponges and collect oil by capillary action or suction. Adsorbents rely on the large surface area, the chemical affinity of the sorbents for the spilled oil, and chemical constituents including their porosity, molecular structure and change in volume. Absorbents work best on light, less viscous oils, while adsorbents work best on heavy, sticky, more viscous oils. In some cases, a sorbents material may utilize both techniques for oil recovery.

Walkup et al., [3] reported that an oil spill cleanup is a question of options and not solutions. Even though no oil spill cleanup system is likely to be completely effective. Sorbents are one of the most widely used methods for compacted oil spills in the sea. The most widely used sorbent is polypropylene (PP) due to its oleophyllic and hydrophobic characteristic [4]. Poile [5] discusses the collection and cleaning methods available in the oil spill. He found that the natural and biodegradable sorbents have particular advantages over synthetic sorbents. Johnson et al. [6] report the potential for using cotton fiber for oil spill cleanups. Choi et al. [7, 8] conduct further studies on milkweed and cotton fiber. When the results of these studies are compared to results gained from PP it was shown that milkweed and cotton sorb oil more efficiently, but PP can be reused.

The aim of this work is to evaluate and compare waste PE and PP powders and sheets as oil spill sorbents which can recover oils. Two Egyptian crude oils have been tested as the oil spill substrate in fresh as well as in sea water.

\section{EXPERIMENTAL}

\subsection{Materials}

Crude oils: Two Egyptian crude oils, namely Marine (MB) and Land Belayem (LB) were used as oil spill substrate. These oils represent low and high gravities, resin and asphaltenes contents, respectively. Their general properties are presented in Table 1. Land Belayem crude oil is evidently heavier and more viscous than the Marine, crude oil. Besides it contains higher asphaltenes (6 times larger) and sulfur.

TABLE 1

General characteristics of different crude oils

\begin{tabular}{l|c|c}
\hline Property & MB & LB \\
Density $\mathrm{gm} / \mathrm{cm}^{3}$ at $20^{\circ} \mathrm{C}$ & 0.8731 & 0.9266 \\
API & 30.56 & 21.9 \\
Viscosity at $100^{\circ} \mathrm{F} \mathrm{cSt}$ & 11 & 111 \\
S content $\%$ & 1.7 & 2.8 \\
Asphaltene \% Wt & 1.5 & 9 \\
R/A & 7.64 & 1.62 \\
\hline
\end{tabular}

\subsection{Oil Sorption Tests}

$1 \mathrm{ml}$ of crude oil was mixed with $50 \mathrm{ml}$ of sea or fresh water in a batch contactor using stirring for $2 \mathrm{~min}$, then left for $20 \mathrm{~min} .0 .20,0.50,0.75$ or $1.00 \mathrm{~g}$ of the waste plastic powder or sheet were added to the oil/water mixture and agitated for $10 \mathrm{~min}$. The water was then completely separated from the oil containing the waste plastic. The oil was then extracted with chloroform and its amount was determined colorimetrically using UV Shimadzu spectrophotometer model 120-02 at a wavelength of $340 \mathrm{~nm}$. Figures 1-6 are plots of the sorption efficiency of the PE and PP either in powder or sheet forms to sorb the light and heavy crude oils from water. 


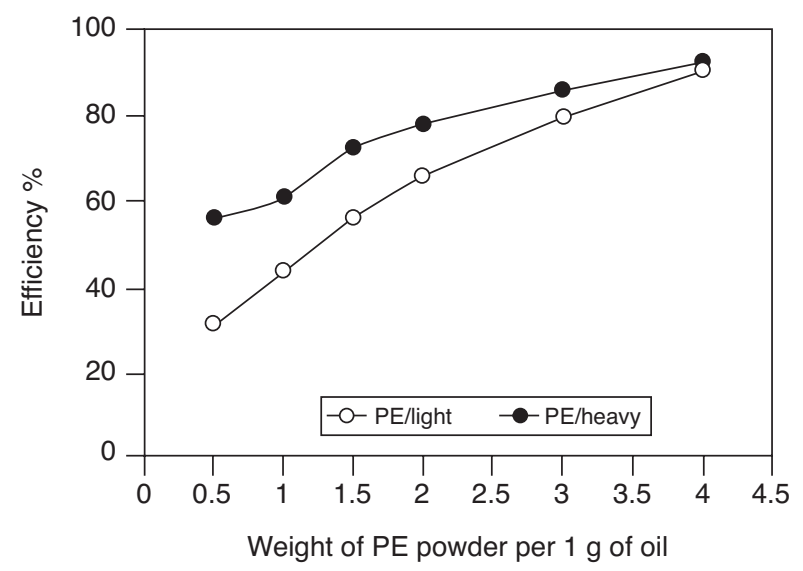

Figure 1a

Sorption efficiency of light and heavy crude oils on PE powder.

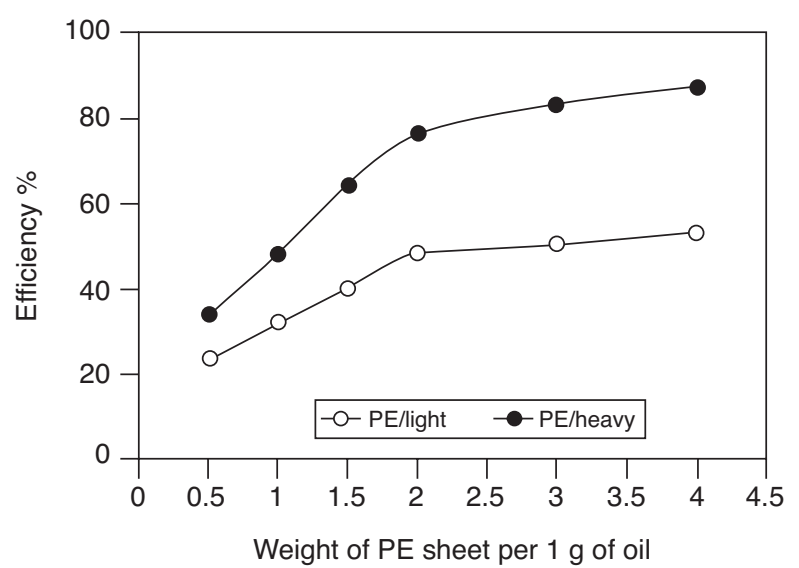

Figure 2a

Sorption efficiency of light and heavy crude oils on PE sheet.

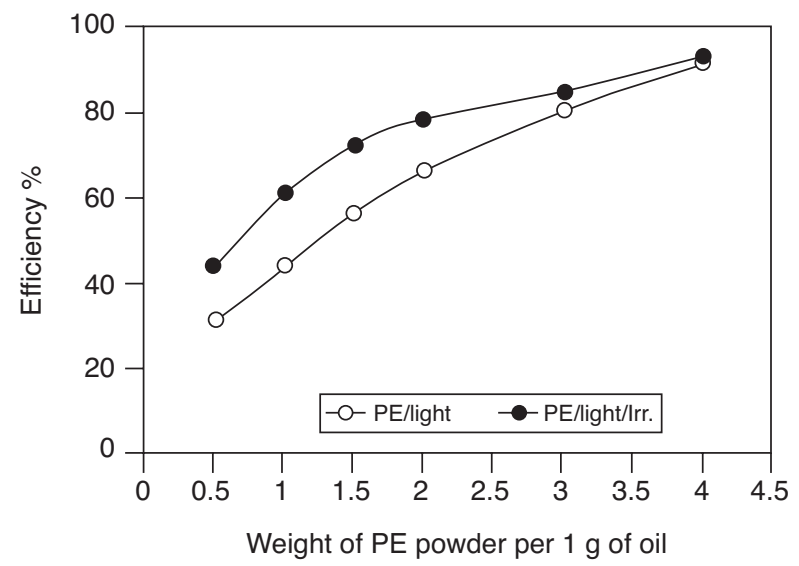

Figure $3 a$

Sorption efficiency of light crude oil on PE powder before and after irradiation with 3 Mrad.

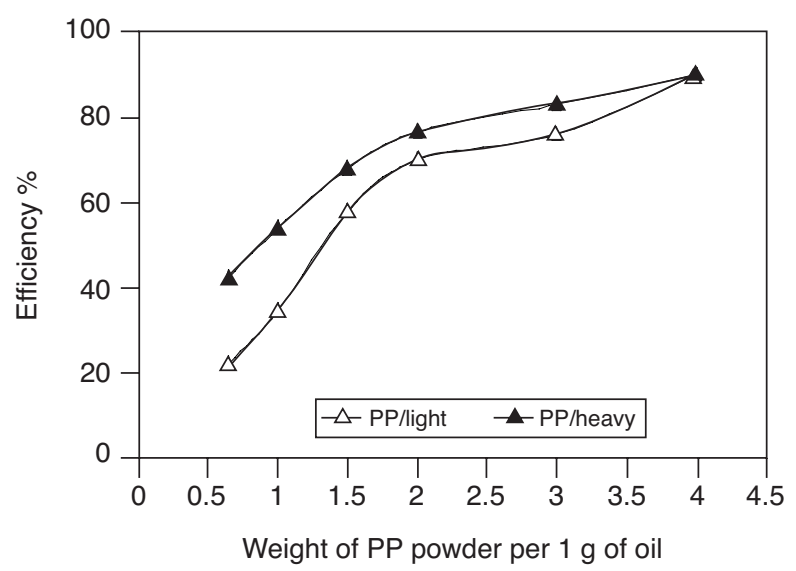

Figure $1 b$

Sorption efficiency of light and heavy crude oils on PP powder.

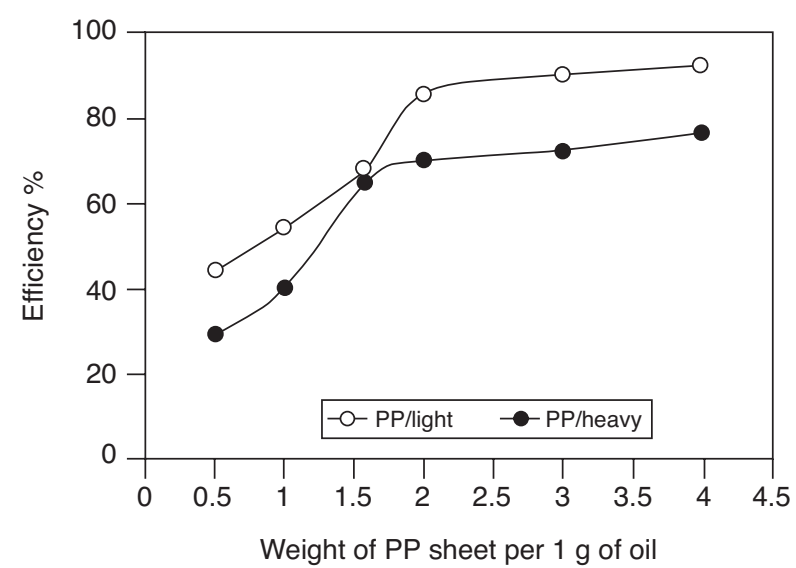

Figure $2 b$

Sorption efficiency of light and heavy crude oils on PP sheet.

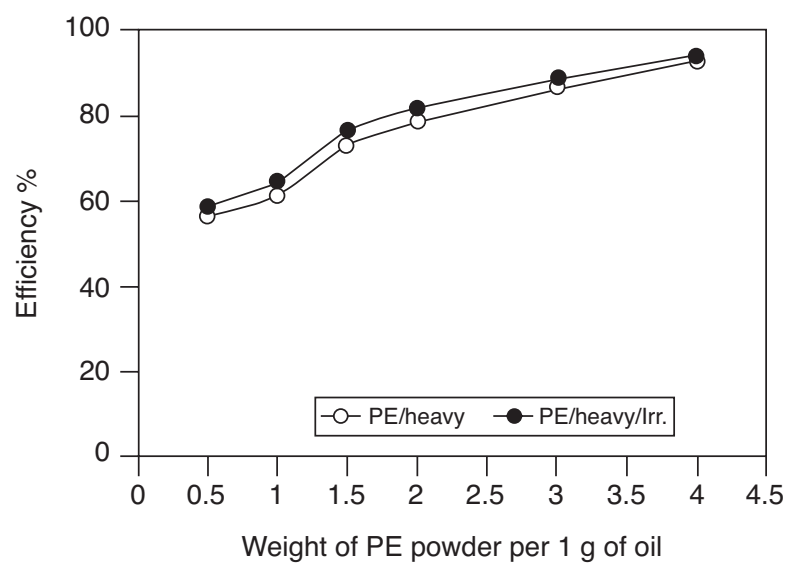

Figure $3 b$

Sorption efficiency of heavy crude oil on PE powder before and after irradiation with 3 Mrad. 


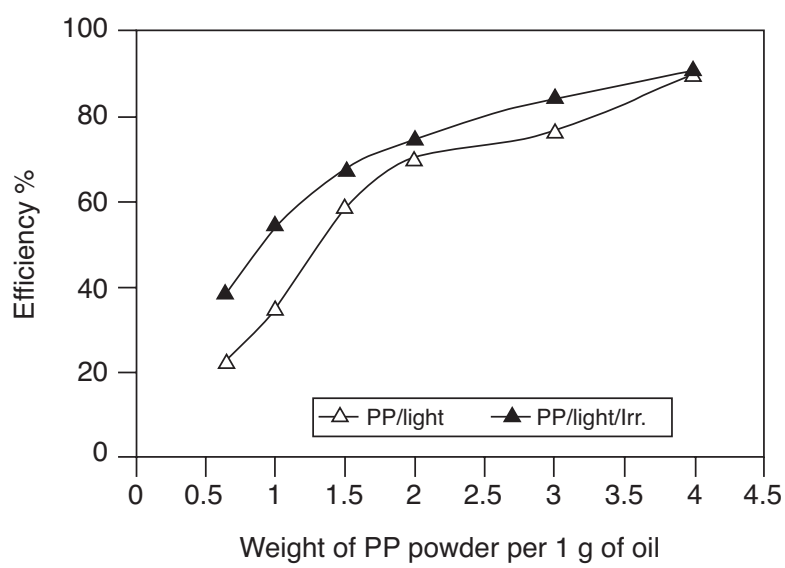

Figure 4a

Sorption efficiency of light crude oil on PP powder before and after irradiation with $3 \mathrm{Mrad}$.

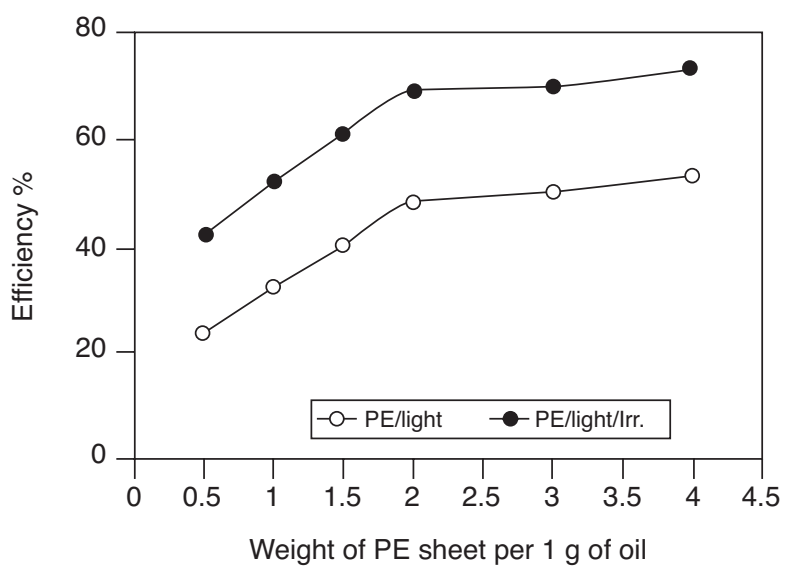

Figure 5a

Sorption efficiency of light crude oil on PE sheet before and after irradiation with $3 \mathrm{Mrad}$.

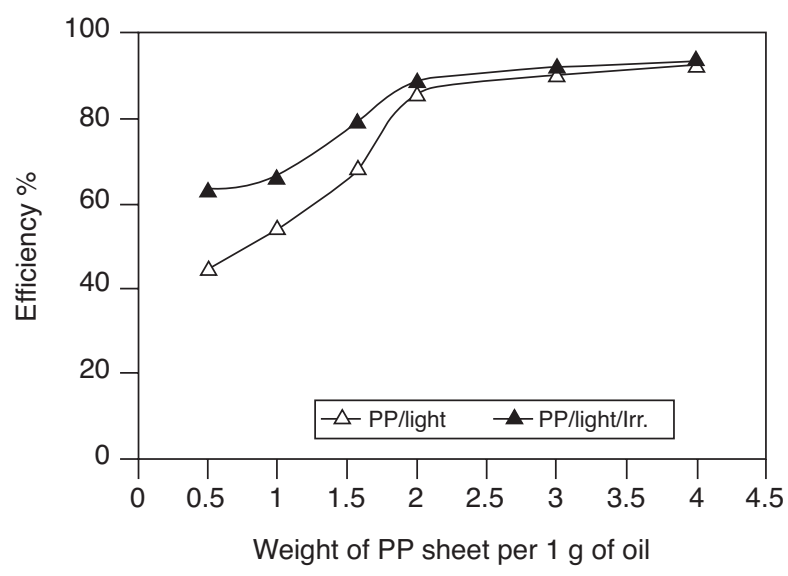

Figure 6a

Sorption efficiency of light crude oil on PP sheet before and after irradiation with 3 Mrad.

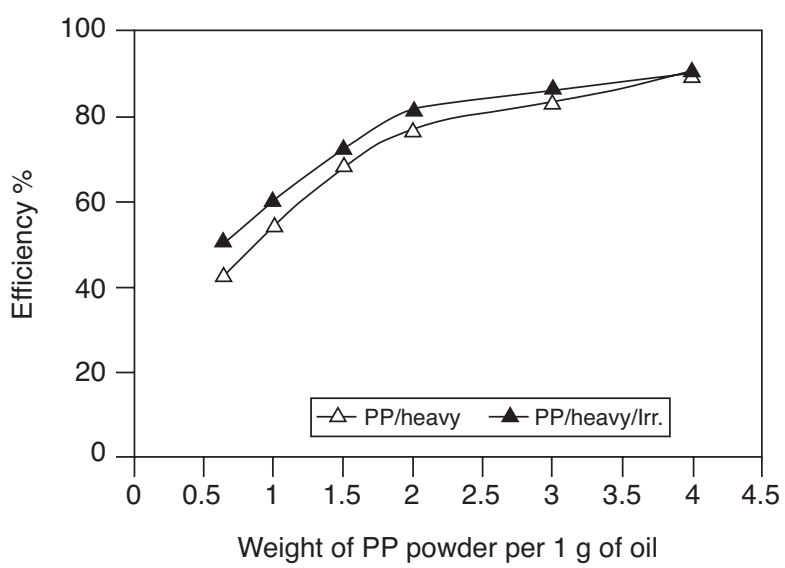

Figure $4 b$

Sorption efficiency of heavy crude oil on PP powder before and after irradiation with $3 \mathrm{Mrad}$.

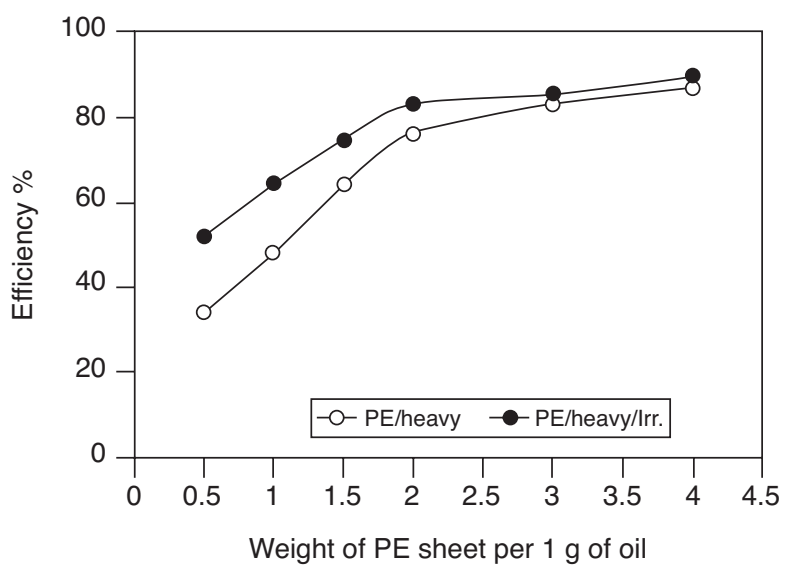

Figure 5b

Sorption efficiency of heavy crude oil on PE sheet before and after irradiation with $3 \mathrm{Mrad}$.

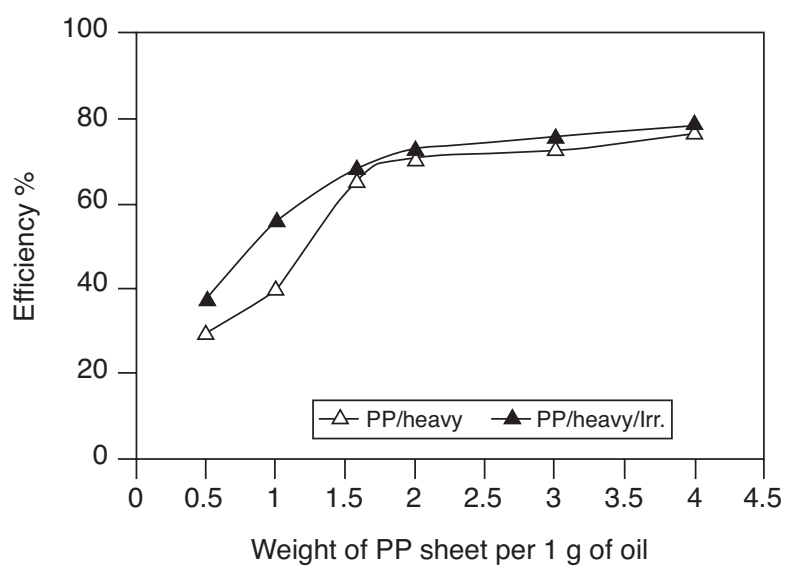

Figure $6 \mathrm{~b}$

Sorption efficiency of heavy crude oil on PP sheet before and after irradiation with $3 \mathrm{Mrad}$. 
The sorption efficiency is defined in this work as:

Efficiency $100 \%=\frac{\text { weight of oil sorbed by the polymer }}{\text { weight of initial oil in water }} \times 100$

TABLE 2

DSC of the PE and PP

\begin{tabular}{l|c|c}
\hline Polymer Samples & $\begin{array}{c}\text { Melting peak } \\
\text { temperature }{ }^{\circ} \mathrm{C}\end{array}$ & $\Delta \mathrm{H} \mathrm{J} / \mathrm{g}$ \\
\hline PE powder (blank) & 121.5 & 10.861 \\
\hline PE powder after soak up oil & 121.833 & 6.560 \\
\hline $\begin{array}{l}\text { PE powder after irradiation } \\
\text { and soak up oil }\end{array}$ & 122.5 & 9.625 \\
\hline PE sheet (blank) & 124.333 & 26.303 \\
\hline PE sheet after soak up oil & 124.333 & 5.009 \\
\hline $\begin{array}{l}\text { PE sheet after irradiation } \\
\text { and soak up oil }\end{array}$ & 124.0 & 11.018 \\
\hline PP powder (blank) & 112.833 & 19.497 \\
\hline PP powder after soak up oil & 108.666 & 7.574 \\
\hline $\begin{array}{l}\text { PP powder after irradiation } \\
\text { and soak up oil }\end{array}$ & 110.166 & 12.631 \\
\hline PP sheet (blank) & 168.500 & 29.712 \\
\hline PP sheet after soak up oil & 167.000 & 9.374 \\
\hline $\begin{array}{l}\text { PP sheet after irradiation } \\
\text { and soak up oil }\end{array}$ & 167.666 & 67.043 \\
\hline
\end{tabular}

\subsection{Differential Scanning Calorimetric Examination (DSC)}

DSC measurements of the polymers were carried out using a Perkin-Elmer DSC apparatus with DSC-7 data station. $10 \mathrm{mg}$ of the polymer was placed in the analyzing DSC standard aluminum cell at room temperature. The cell system was heated at a rate of $10 \mathrm{~K} \mathrm{~min}^{-1}$ and the full scale range was 25 $\mathrm{mW}$. The data withdrawn from DSC thermograms are given in Table 2. The selected DSC thermograms of PE and PP sheets in absences and presence of $\gamma$-irradiation after sorbing the oil are illustrated in Figures 7 and 8, respectively.

\subsection{Scanning Electron Microscopic Examination (SEM)}

The scanning electron microscope (SEM) JEOL.JSM-5400 was used to observe and characterize the current materials. The signals observed clarify surface topography of the materials. Dried PE ad PP samples were frozen in liquid nitrogen and then cracked into pieces to achieve a generally smooth fracture. The pieces were sputter-coated with gold and examined using a JEOL.JSM-5400 scanning electron microscope. SEM micrographs are shown in Figures 9-12.

\section{RESULTS AND DISCUSSION}

In this investigation we are trying to solve the problem of the vast accumulation of the waste plastic sheets made of polyethylene (PE) and polypropylene (PP) which increase day after day in huge amounts such that their disposal became a serious problem. Also, the oil spills in aquatic locations represent another problem including not only the aquatic inhabitation but also its being a loss of the valuable crude oil material. Therefore, we use the waste PE and PP either in the form of powder or in the form of sheets for sorbing the oil spill from fresh and sea water. Fortunately, we found no measurable difference between the data obtained using the oil in fresh or sea water. This indicates that the salinity of the water

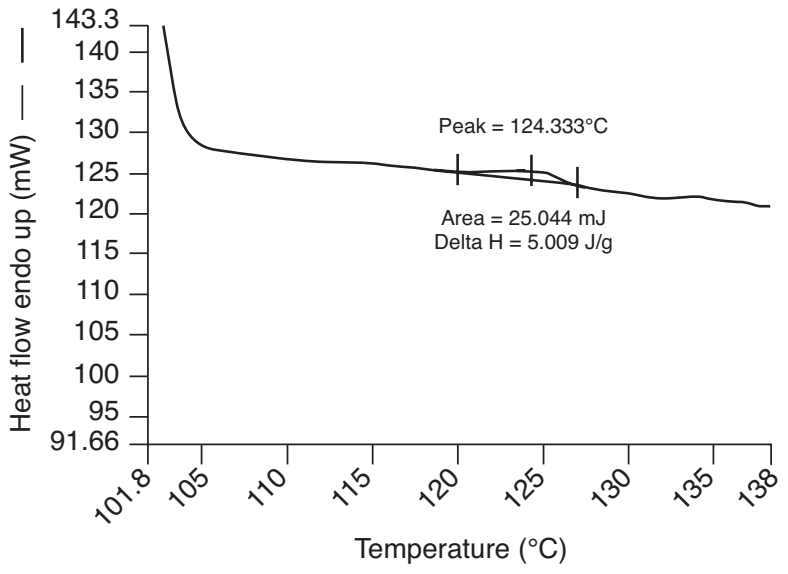

Figure 7a

DSC of PE sheet after soak up oil, $\mathrm{T}_{\mathrm{m}}=124.333^{\circ} \mathrm{C}, \Delta \mathrm{H}_{\mathrm{m}}=$ $5.009 \mathrm{~J} / \mathrm{g}$.

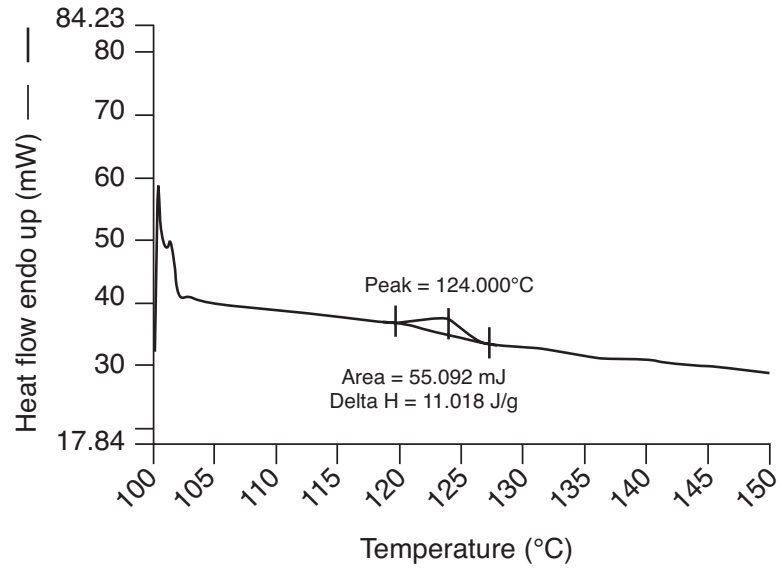

Figure $7 b$

DSC of PE sheet after irradiated by 3 Mrad and soak up oil, $\mathrm{T}_{\mathrm{m}}=124.0^{\circ} \mathrm{C}, \Delta \mathrm{H}_{\mathrm{m}}=11.018 \mathrm{~J} / \mathrm{g}$. 


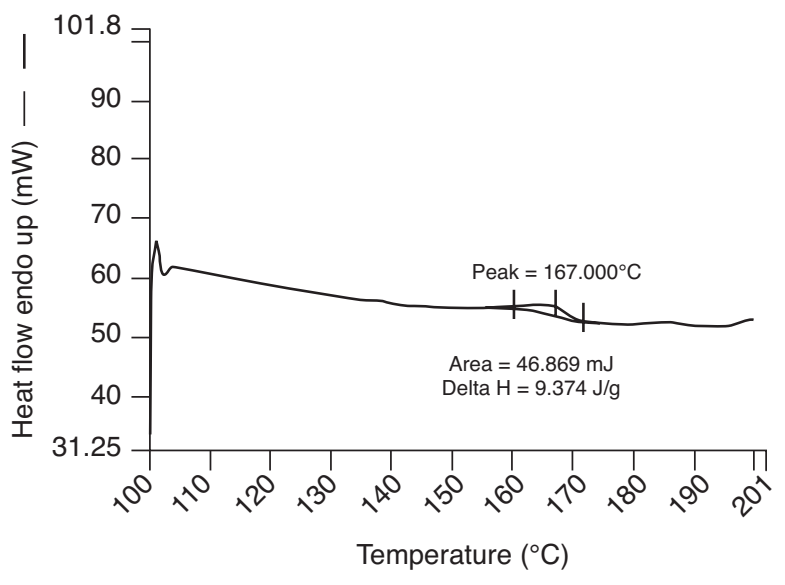

Figure 8a

DSC of PP sheet after soak up oil, $\mathrm{T}_{\mathrm{m}}=167.000^{\circ} \mathrm{C}, \Delta \mathrm{H}_{\mathrm{m}}=$ $9.374 \mathrm{~J} / \mathrm{g}$.

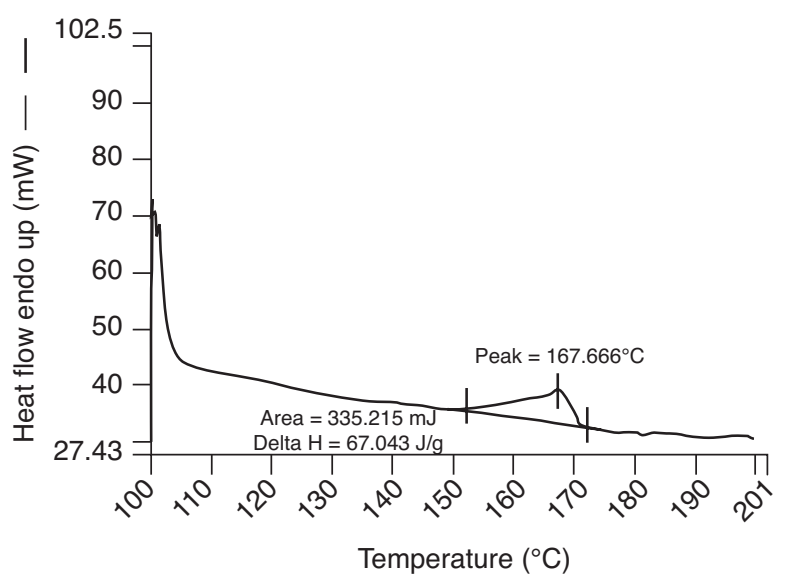

Figure 8b.

DSC of PP sheet after irradiated by 3 Mrad and soak up oil, $\mathrm{T}_{\mathrm{m}}=167.666^{\circ} \mathrm{C}, \Delta \mathrm{H}_{\mathrm{m}}=67.043 \mathrm{~J} / \mathrm{g}$. is ineffective, and the oil sorption by the waste polymers is a direct relationship between the oil and the polymer, with no interference from the aqueous phase. Although Choi et al., $[7,8]$ stated that polymers are less effective than natural sorbents, we use these polymers (PE and PP) because the oil can be separated easier and the recovery is much larger than from the natural sorbents. Moreover, the polymers (plastics) are more stable and can be reused for further sorption.

\subsection{Effect of Waste Polymer Type on the Oil Absorption Capacity}

In this work, we use two Egyptian crude oils; a relatively lighter crude (MB) and a heavier one (LB) (Table 1), to shed light on the effect of viscosity and density of the crude oil on the capability of the waste plastics to sorb the oil spill. The Cooper and Gausemel [9] procedure has been followed in this work. The waste sheets of PE or PP have been washed, dried then cut into one-inch pieces, or crushed in irregular powdered material. The sorption tests have been performed to determine the weight of crude oil sorbed per $1 \mathrm{~g}$ of the waste plastic, whether in the form of powders or sheets. Figures 1-6 show that, in general, the sorption efficiency of a waste plastic increases with increasing the plastic to oil ratio. In general, the increase of the sorption efficiency is greater during the plastic/oil ratio from 0.5 to 2 , beyond which a further increase of this ratio up to 4 results in a lees effective oil sorption.

Data in Figures 1a, 1b and 2a show that the PE waste either as powder or sheet and PP as powder have more efficiently sorbed the heavier crude oil (LB) than the lighter one (MB). Evidently, the sorption capacity of PE sheet for the heavy oil is much more higher than for the lighter oil, particularly with increasing the weight of PE sheet/oil ratio (Fig. 2a). On the contrary, it is found that the reverse occurs with respect to the sorption efficiency of the PP sheets (Fig. 2b), where the lighter crude oil is more efficiently sorbed than the heavier one.

The thickeness of PE and PP sheets are 50-60 $\mu \mathrm{m}$ and 30-40 $\mu \mathrm{m}$, respectively. So, the thinner PP sheets have higher collective surface area per a given weight of the oil than the thicker sheets of PE, hence the lighter crude oil will find better opportunity to be soaked up by the thin sheets of PP. Wei, et al. [10] reported that the polypropylene is the ideal material for marine oil-spill recovery due to its low density, low water uptake and excellent physical and chemical resistance. They also evaluated different forms of polypropylene nonwoven sorbents in terms of initial oil-sorption capacities and oil-retention properties. Their investigation revealed that the fibre diameter, sorbent porosity and oil property are the most important factors in the oil-sorption performance of polypropylene nonwoven sorbents.

\subsection{Effect of $\gamma$-Irradiation on the Efficiency of Waste Polymers for Oil Sorption.}

The effect of $\gamma$-irradiation on the efficiency of the powdered waste PE and PP plastics for sorption of the light crude oils are shown in Figures 3a and 4a, respectively, whereas, the irradiation effect on the sorption efficiency of these powdered waste plastics for the heavy crude oil are shown in Figures $3 \mathrm{~b}$ and $4 \mathrm{~b}$, respectively. Figures $3 \mathrm{a}$ and $4 \mathrm{a}$ show some significant enhancement of the sorption efficiency of the lighter MB oil, via $\gamma$-irradiation particularly, at the lower plastic/oil ratios.

However, the effect of $\gamma$-irradiation of the powdered PE and PP on the heavy oil sorption (Figs. $3 b$ and $4 b$ ) is insignificant at all waste plastic/oil ratios, which may be attributed to the larger effect of cross-linking of the polymers (PE and PP) on inhibiting the heavy oil sorption. The more 


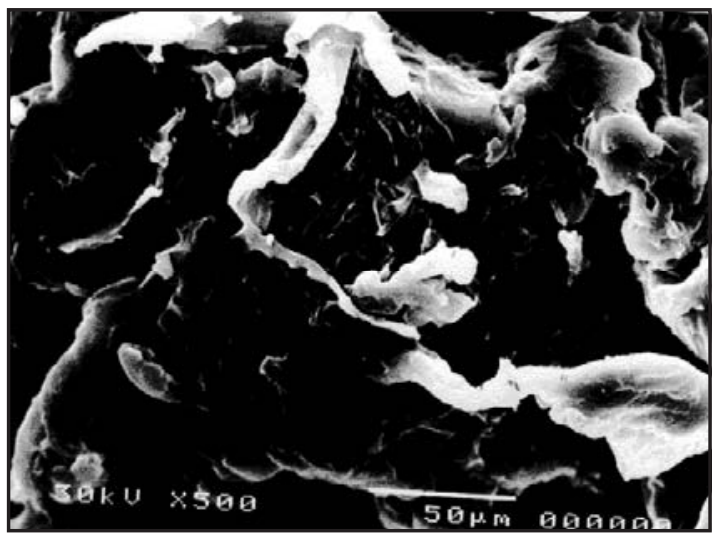

Figure 9a

SEM micrograph of the PE powder before adsorption of oil spill.

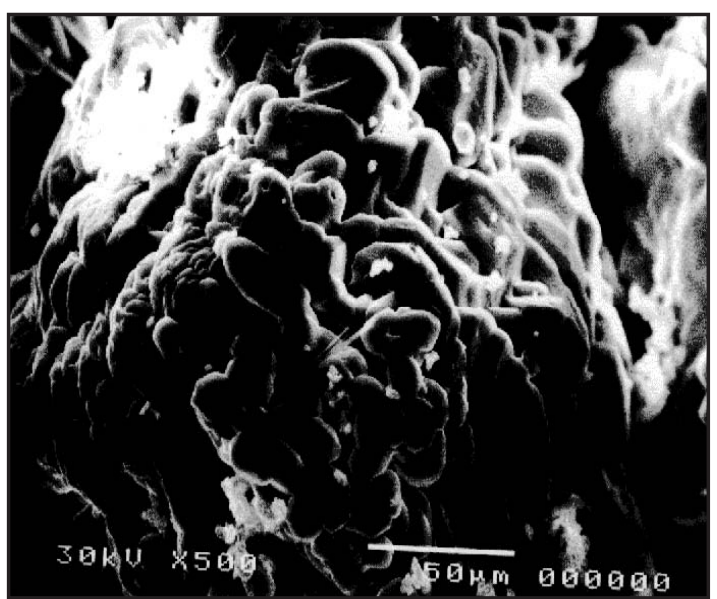

Figure 9.b

SEM micrograph of the PE powder after adsorption of oil spill.

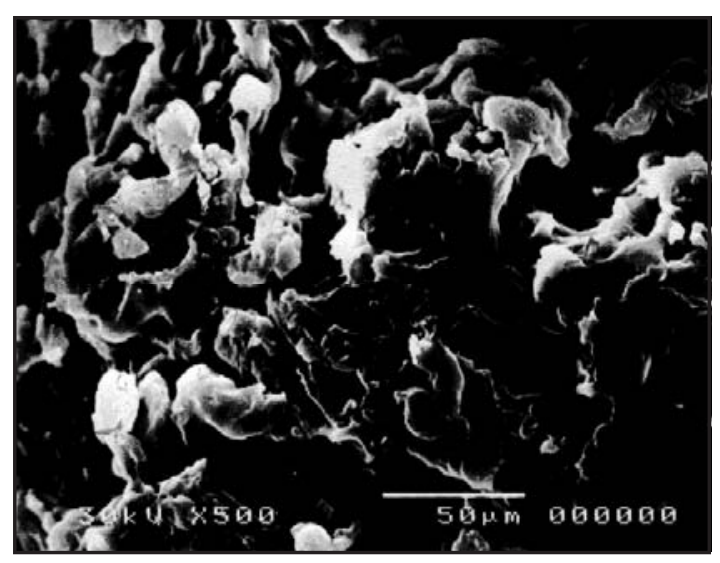

Figure 9c

SEM micrograph of irradiation PE powder at $3 \mathrm{Mrad}$ followed by absorbing oil spill.

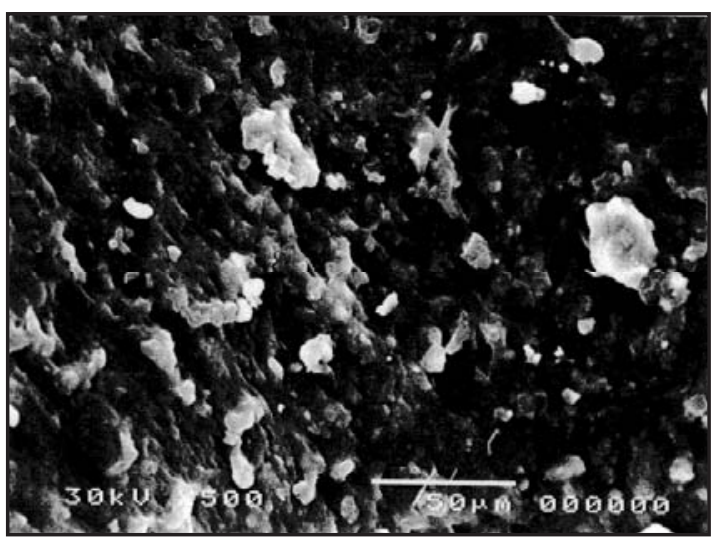

Figure 10a

SEM micrograph of the PP powder before adsorption of oil spill.

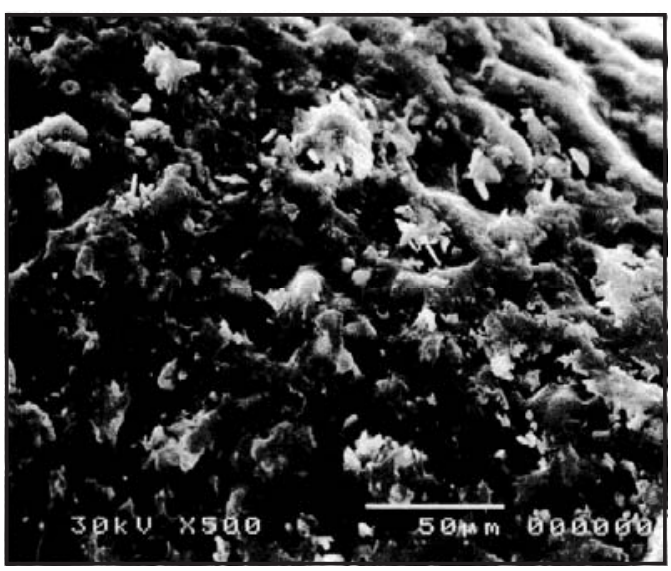

Figure 10b

SEM micrograph of the PP powder after adsorption of oil spill.

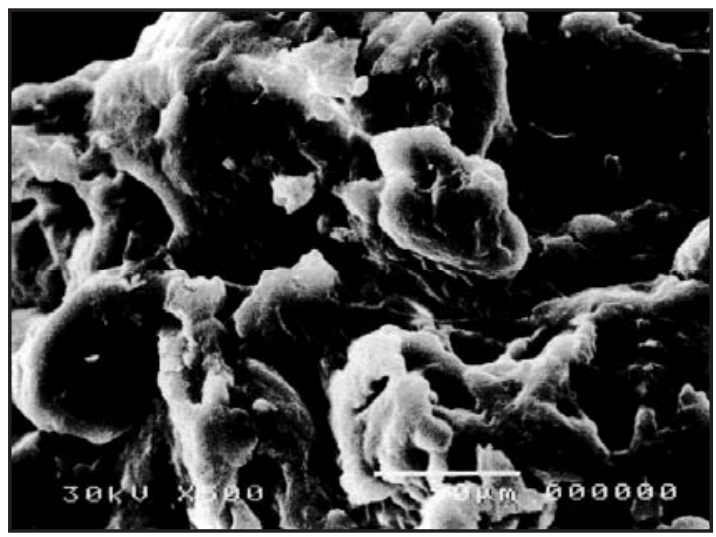

Figure 10c

SEM micrograph of irradiation PP powder at $3 \mathrm{Mrad}$ followed by absorbing oil spill. 


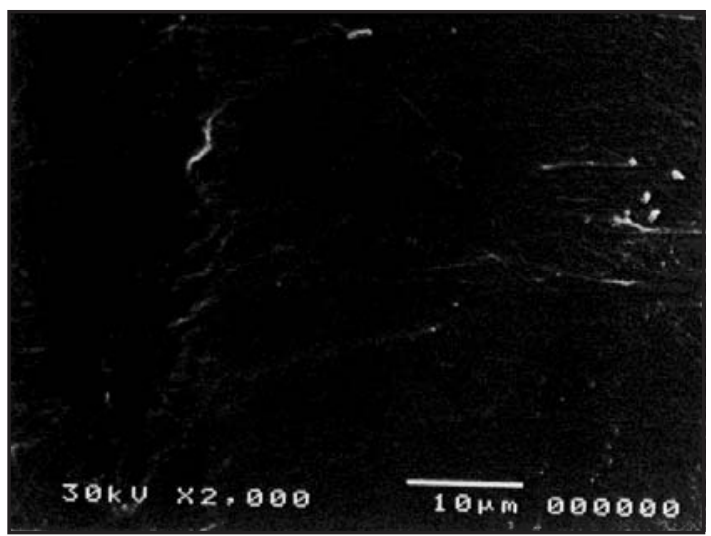

Figure 11a

SEM micrograph of the PE sheet before adsorption of oil spill.

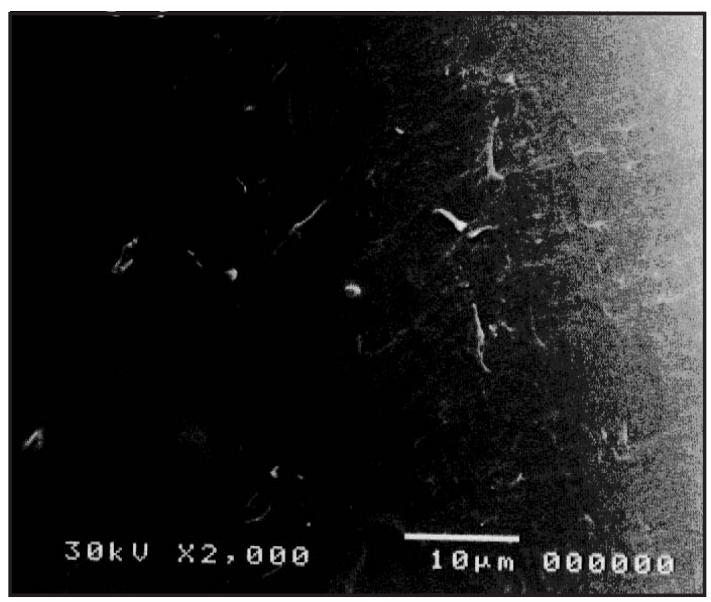

Figure 11b

SEM micrograph of the PE sheet after adsorption of oil spill.

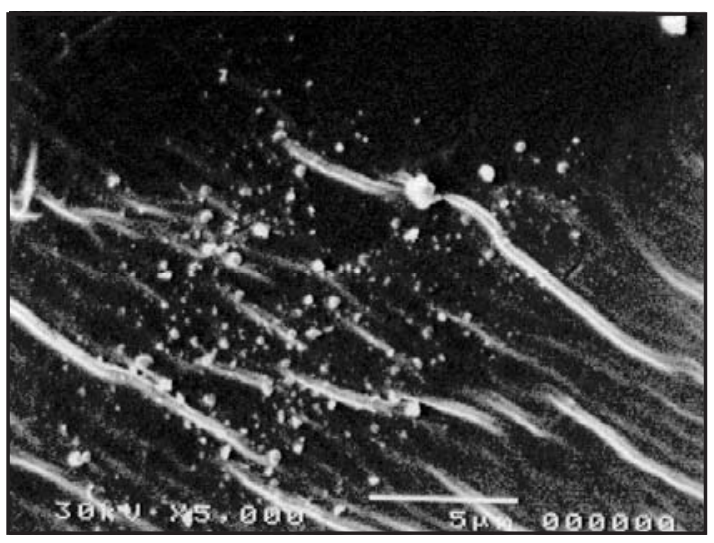

Figure 11c

SEM micrograph of irradiation PE sheet at 3 Mrad followed by absorbing oil spill.

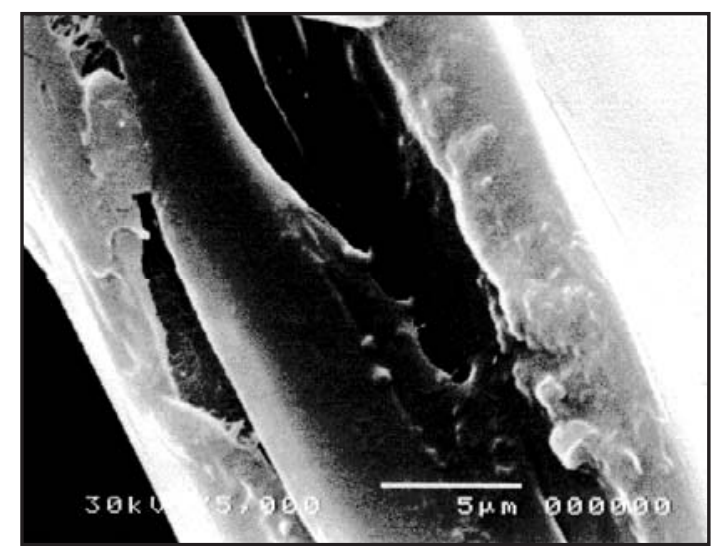

Figure 12a

SEM micrograph of the PP sheet before adsorption of oil spill.

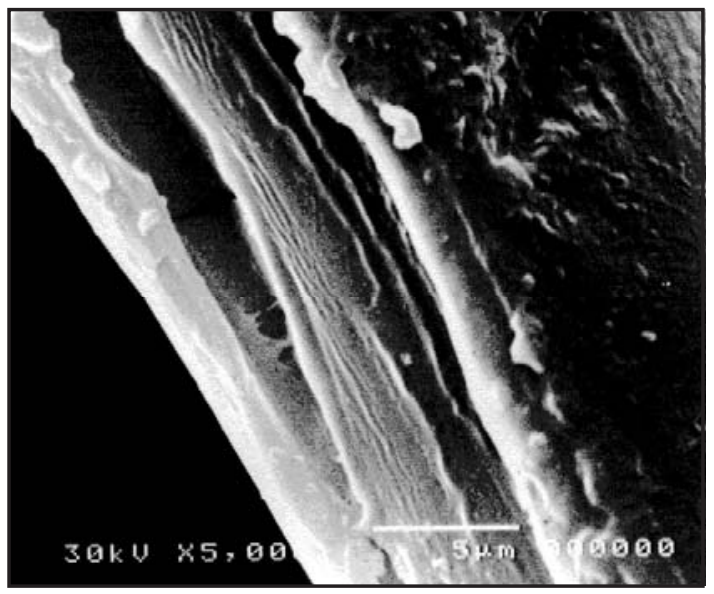

Figure $12 b$

SEM micrograph of the PP sheet after adsorption of oil spill.

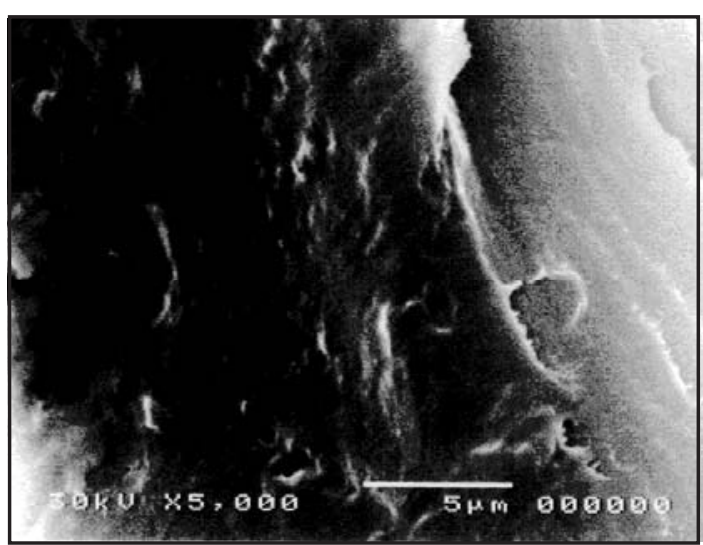

Figure 12c

SEM micrograph of irradiation PP sheet at 3 Mrad followed by absorbing oil spill. 
viscous oil (LB) molecules does not appear capable of overcompensating the cross linking enhancement produced by irradiation, hence, the difference between the quantity of the heavy oil sorbed on the irradiated powdered polymer is insignificant (Figs $3 b$ and $4 b$ ).

Figures $5 \mathrm{a}$ and $5 \mathrm{~b}$ show the effect of $\gamma$-irradiation on the light and heavy oils sorption on the PE sheets, respectively. The sorption of light oil is significant at all waste plastic/oil ratios examined, whereas the heavy oil sorption is only significant at the lower plastic/oil ratios then becomes low at larger ratios of 2 to 4 . However, irradiation of PP sheets (Figs. $6 a$ and $6 b$ ) is only effective in light and heavy oils sorption at lower plastic/oil ratios decreases at larger ratios. Evidently, there is no significant difference between the effect of irradiation of waste PP on its efficiency to sorbe the light or heavy crude oils.

Subjecting all of the current waste polymers, whether in the form of powder or in the form of sheets to $3 \mathrm{Mrad}$ of $\gamma$ irradiation has increased the capability of these polymers to sorb the two oils under investigation (MB and LB). This can be attributed to cross-linking enhancement of the polymers. Irradiation of the polymers in air creates active sites on the polymer surface, due to the formation of conjugated structures in the polymer chains (crosslinking network [11, 12]). This crosslinking structure allows greater penetration of oil into the polymer matrix. Since the polymer surface is not the only factor affecting adsorption, but in this case the chemical structure of the polymer has also a great effect [13-15].

The crosslinking mechanism possibly involves the production of polymer radicals at neighbouring sites on adjacent chains, accompanied by the loss of molecular hydrogen as follows:

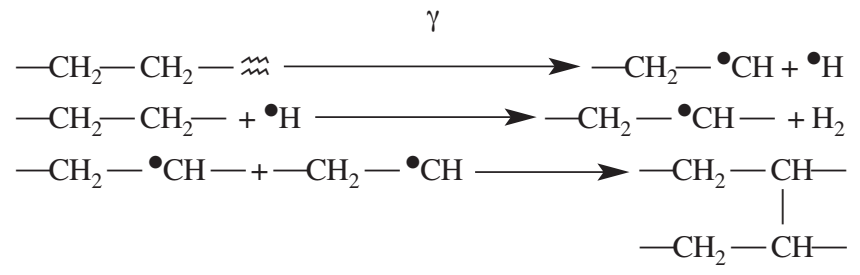

\subsection{DSC Measurements}

Examination of the current PE and PP powdered and sheet samples can be assumed of different sources (Table 2). The melting point $\left(\mathrm{T}_{\mathrm{m}}\right)$ of PP powder is significantly lower $\left(112.8^{\circ} \mathrm{C}\right)$ than that of the PP sheets $\left(168.5^{\circ} \mathrm{C}\right)$. However, the melting points of the $\mathrm{PE}$ powders and sheets are not significantly varying (121.5 and $124.3^{\circ} \mathrm{C}$, respectively). These values indicate that the PP powder and sheets are of different sources, whereas the respective PE forms may be of the same source. With respect to the thermal properties of the polymers under investigation, PP in general requires higher latent heat of fusion than PE. The results also shows that the melting point of the current irradiated and unirradiated polymers used for sorbing the crude oil spill have slightly decreased than the melting point of the control samples. This can be attributed to absorption of a small fraction of the oil in the internal structure of the polymer. However, in comparing the $\Delta \mathrm{H}_{\mathrm{m}}$ values in Table 2 of the irradiated PE and PP samples with those of the unirradiated samples. It is found that the former gives lower enthalpy values than the latter sample, indicating that significant numbers of active centers have been formed in the current polymer via a dose of $3 \mathrm{Mrad}$ $\gamma$-irradiation. Evidently, Table 2 shows that all the powdered and sheet polymers suffer some decrease in $\mathrm{T}_{\mathrm{m}}$ and $\Delta \mathrm{H}_{\mathrm{m}}$ after oil spill absorption and $\gamma$-irradiation. Therefore, this decrease for the irradiated films of PE and PP powder and sheet is due to restriction of chain mobility and disordering of their structures caused by such crosslinks $[16,17]$. However, the decrease of $\Delta \mathrm{H}_{\mathrm{m}}$ due to the oil sorption is greater than that due to $\gamma$-irradiation, indicating induced larger stability which substantiates the reuse of these polymers, perhaps several times later. The DSC of $\gamma$-irradiated and non-irradiated PE and PP sheets after oil soak up are shown in Figures 7 and 8, respectively.

\subsection{Scanning Electron Microscope (SEM) of the polyethylene (PE) and polypropylene (PP)}

SEM of the PE and PP powders and sheets before and after oil sorption are shown in Figures 9-12.

The PE and PP powders (Figs. 9a and 10a, respectively) exhibit the groove structures characteristic for these polymers. However, the PP powder shows more transparency than the PE powder which is attributed to a less dense structure of the latter. Moreover, the particle size of the PP powder is clearly smaller than that of the PE powder. Fig. $9 \mathrm{~b}$ and $10 \mathrm{~b}$ show the SEM micrographs of PE and PP powders after sorbing the oil followed by washing with chloroform then drying. Deeper grooves appear to be formed in the powders of both polymers. This may indicate that the oil sorbed on the two polymers causes swelling of the polymers particles. The oil adsorbed on the polymers could have forced the ongoing oil to be accumulated within the internal surfaces.

Figures $9 \mathrm{c}$ and 10c are the SEM micrographs obtained for the primarily irradiated PE and PP powders with 3 Mrad dose followed by oil sorption, washing and drying. Evidently, irradiation has enhanced cross-linking and degradation of the two polymers, resulting in deeper cavities, roughness and deformation of the polymers structures. The $\gamma$-irradiation seems more effective on the PP powder than on the PE powder since PP powder seems more spongy. This can be attributed to the lower density of the PP powder where the polymer degradation is more enhanced.

On the other hand, the SEM micrograph of the PE sheet (Fig. 11a) shows a dense oriented structure characteristic of PE films, whereas the PP sheet (Fig.12a) exhibits smooth 
surface of folded lighter layers. Figure $11 \mathrm{~b}$ shows some small protrusions attributed to captured oil spill droplets absorbed by scratches scattered on the PE sheet surface. Again, Figure 12b shows an increased number of the folded lighter layers of the PP polymer due its larger capability to soak up oil. Furthermore, $\gamma$-irradiation of PE sheet (Fig. 11C) appears to have significantly enhanced formation of small protrusions as well as quasi-parallel striations due to oil absorption and cross-linking. Also, the PP sheet (Fig. 12c) seems to be largely swollen with simultaneous formation of hole-like grooves. This structure may have increased the surface area of the PP sheet resulting in enhancing oil soaking. In general, it can be assumed that the PE and PP sheets are smoother and less grooved compared to the corresponding powders.

\section{CONCLUSION}

Polyethylene powder and sheets as will as polypropylene powder absorb more strongly heavier crude oils than lighter ones. Nevertheless, polypropylene sheets sorb more light oil than heavier oil.

The DSC and SEM examinations are useful to study the capability of common waste polymers to be reused several times.

$\gamma$-Irradiation of the waste polymers with $3 \mathrm{Mrad}$ dose enhances their efficiency for oil sorption.

\section{REFERENCES}

1 Masaki Saito, Nobuyoshi Ishii, Suguru Ogura, Shinji Maemura and Hirohisa Suzuki (2003) Spill Science \& Technology bulletin, 8, 5-6, 475-482.

2 Ghalambor, A. (1995) Evaluation and characterization of sorbents in removal of oil spills, Louisiana Oil Spill Coordinator's Office, Louisiana Applied Oil Spill Research and Development Program, Baton Rouge, Louisiana, OSRADP Technical Report Series 95-006.
3 Walkup, P.C., Polentz, L.M., Smith, J.D. and Peterson, P.L. (1969) Study of equipment and methods for removing oil from harbor waters. Proceedings of Joint Conference on Prevention and Control of Oil Spills, 15-17 December, New York, 237-248.

4 Schatzberg, P. (1971) Investigation of sorbents for removing oil spills from waters. U.S. Coast Guard Report No. 724110.1/2/1, U.S. Coast Guard Headquarters, Washington, D.C., 30.

5 Poile, C.A. (1990) Cleaning up oil spill"s. Probe Post. 12 (3/4), 13-15.

6 Johnson, R.F., Manjerakar, T.G. and Haligan, J.E. (1973) Removal of oil from water surfaces by sorption on unstructured fibers. Environmental Science and Technology. 4, 439-443.

7 Choi, H. and Cloud, R.M. (1992) Natural sorbents in oil spill cleanup. Environmental Science and Technology. 26, 4 April, 772-776.

8 Choi, H., Kwon, H. and Moreau, J.P. (1993) Cotton nonwovens as oil spill cleanup sorbents. Textile Research Journal. 63, 4, 211-218.

9 Cooper, D. and Gausemel, I. (1993) Oil spills sorbents: Testing protocol and certification listing program. Oil Spill Conference: Prevention, Preparedness, Response, 29 March, Tampa, Fla., 549-551.

10 Wei, Q.F., Mather, R.R., Fotheringham, A.F. and Yang, R.D. (2003) Spill Science \& Technology bulletin. 46, 6, 780-783, June.

11 Chapiro, A. (1962) Radiation Chemistry of Polymeric System Interscience, John Wiley\&Sons, New York, 696.

12 Sweeting, O.J. (1975) The Science and Technology of Polymer Films, Wiley Interscience, New York, 11, 16.

13 Meitzner, E.F. and Aline, J.A. (1963) British patents 932, 125 and 932, 126, Crosslinked Copolymer.

14 Vernon, F. and Shah, T., (1983) Reactive Polymer, 1, 301.

15 Barrie, J.A., Diffusion Polymer, Crank, J. and Park, G.S. (1968) Eds. Academic Press, London, 8.

16 Hegazy, E.A., Sasuga, T. and Seguchi, T. (1992) Polymer, 33, 2911.

17 Brady, D.G. (1976) J. Appl. Polym. Sci., 20, 2541.

Final manuscript received in May 2005

Copyright $($ ㅇ 2006 Institut français du pétrole

Permission to make digital or hard copies of part or all of this work for personal or classroom use is granted without fee provided that copies are not made or distributed for profit or commercial advantage and that copies bear this notice and the full citation on the first page. Copyrights for components of this work owned by others than IFP must be honored. Abstracting with credit is permitted. To copy otherwise, to republish, to post on servers, or to redistribute to lists, requires prior specific permission and/or a fee: Request permission from Documentation, Institut français du pétrole, fax. +33147527078 , or revueogst@ifp.fr. 